\title{
ANALYSIS - WHAT IS LEGAL MEDICINE?
}

\section{Author Information:}

\author{
ROY G. BERAN \\ M.D (University of NSW, Australia)., \\ F.R.A.C.P (Royal Australian College of GP's, Australia)., \\ F.R.C.P (Royal College of Physicians, England)., \\ F.R.A.C.G.P (Royal Australasian College of Physicians, Australia),, \\ F.A.C.L.M.(Australian College of Legal Medicine, Australia), \\ F.A.F.P.H.M (Royal Australasian College of Physicians, Australia) \\ F.A.C.B.S. (Australasian College of Biomedical Sciences, Australia) \\ B Leg.S. (Macquarie University, Sydney Australia) \\ Grad. Dip. Tert. Ed. (New England University, Armidale, Australia) \\ Grad. Dip. Further Ed. (Adelaide College of Advanced Education, Australia), \\ M.H.L. (University of Sydney, Australia) \\ CONJOINT ASSOCIATE PROFESSOR UNIVERSITY OF NSW, AUSTRALIA \\ PROFESSOR, SCHOOL OF MEDICINE, GRIFFITH UNIVERSITY, BRISBANE, AUSTRALIA
}

\section{Author's Contact Details:}

Address: Suite 5, level 6, 12 Thomas Street

Chatswood NSW 2067, Australia

Ph: +61029411 4991

Fax: +61 0294114991

Roy.beran@unsw.edu.au

(preferred method of communication is e-mail)

\section{Key Words:}

Specialty, Legal Medicine, Assessment, Expert Witness, Ethics, Forensic Medicine

\section{Word Count:}

\section{1 (excluding abstract)}




\title{
ANALYSIS - WHAT IS LEGAL MEDICINE?
}

\begin{abstract}
Legal Medicine addresses the interface between medicine and law in health care.

The Australian College of Legal Medicine (ACLM) established itself as the peak body in legal and forensic medicine in Australia. It helped establish the Expert Witness Institute of Australia (EWIA), the legal medicine programme at Griffith University and contributes to government enquiries.

Public health, disability assessment, competing priorities of privacy verses notification and determination of fitness for a host of pursuits are aspects of legal medicine.

Complementing the EWIA, the ACLM runs training programmes emphasising legal medicine skills additional to clinical practice, advocating clinical relevance.

Assessment of athletes' fitness and ensuring that prohibited substances are not inadvertently prescribed represent a growing area of legal medicine.

Ethical consideration of health care should respect legal medicine principles rather than armchair commentary.

International Conventions must be respected by legal medicine and dictate physicians' obligations. The NSW courts imposed a duty to provide emergency medical care. Migration and communicable diseases are aspects of legal medicine.

Police surgeons provide a face to legal medicine (which incorporates forensic medicine) underpinning its public perception of specialty recognition.

Legal medicine deserves its place as a medical specialty in its own right.
\end{abstract}




\section{ANALYSIS - WHAT IS LEGAL MEDICINE?}

\section{Introduction}

Legal medicine is the discipline that covers the interface between medicine and law as perceived and practiced by those within the medical profession. It is the medical equivalent of health law but has far greater ramifications for the delivery of health care than hitherto has been appreciated.

In the same way the newly-formed Faculty of Forensic and Legal Medicine (FFLM), of the Royal College of Physicians (London) is seeking to have the discipline recognised as a specialty in its own right in the United Kingdom, so the Australian College of Legal Medicine (ACLM) is preparing a submission to the Australian Medical Council (AMC) to have legal medicine recognised as a specialty and the ACLM to be seen as the peak body representing forensic and legal physicians in Australia.

When the average person is asked, "What is legal medicine?" the answer is usually focused and restricted to expert witness participation and the courts. This is only a small part of a much wider discipline, which encompasses much of what doctors do and has ramifications in all arms of the practice of medicine. It has evolved over the years to the point that it was felt that legal medicine deserved its own representation with its own College and hence, more than a decade ago, the ACLM was formed.

Application of legal medicine has the capacity to touch upon all aspects of the delivery of patient care. It was the basis for the need for tort reform, in Australia, when considering medical negligence. It has resulted in the newly coined terms of, "defensive medicine" or "risk management practice", which impacts on how doctors practise medicine, keep their records, advise patients of the risks and problems associated with various forms of therapy and how they apply informed consent to patient management which respects material risks. Since the landmark case of Rogers $v$ Whitaker, ${ }^{(1)}$ doctors have been acutely aware of the need to give patients sufficient information to allow them to be empowered to make informed decisions as to their management and what is acceptable risk to them. This provides a perfect example of how legal medicine has affected overall health care.

What follows is an analysis of legal medicine as provided by a clinician who has been involved with the ACLM since its foundation and is also proud to have honorary Fellowship of the FFLM.

\section{Historical Background and Evolution}

As was previously reported in this journal ${ }^{(2)}$, the ACLM was formed more than a decade ago when it was realised that legal medicine was no longer an auxiliary discipline but it was a discipline in its own right which required proper training, experience and capacity to support the rest of the profession within this specialised area. The ACLM accepted that forensic medicine was part of legal medicine and more recently The Australian and New Zealand Forensic Medicine Society (ANZFMS) acknowledged the pre-eminence of the ACLM as the peak body in legal medicine and it unilaterally elected to disband and join the ACLM en masse. This was done to achieve the recognition that legal medicine so rightly deserves as a potent and viable specialty area within the broader concept of medicine. Consequent to this merger, the ACLM has become an integral player within the International Symposium of Forensic Sciences held second yearly throughout Australia, having been held in Perth in 2006 and due to be held in Melbourne in 2008. 
Amongst its membership, the ACLM includes doctors with specialty interests in a whole range of medical practice, including obstetrics and gynaecology, neurology, orthopaedic surgery and anaesthetics, to name but a few, as well as including general practitioners who hold post-graduate qualifications, such as the FRACGP. There are also many Fellows trained in forensic medicine and forensic pathology, the two not being necessarily the same discipline. Legal medicine covers forensic physicians and offers training in various aspects of the delivery of health care, including administrative medicine, which cannot be adequately practiced without a clear understanding of the legal ramifications. Legal medicine also incorporates military medicine and the need to respect international conventions and practices to safeguard the rights of participants in conflicts from both sides of that conflict, be they allies or foe, to ensure that humanity respects that which is right and proper.

Consequent of its commitment to enhance the practice of legal medicine, the ACLM was instrumental in the establishment of the Expert Witness Institute of Australia (EWIA) and has collaborated closely with the Institute, such that its Fellows participate in EWIA meetings. The inaugural President of the ACLM, Dr Maurice Wallin, remains one of the Directors of the EWIA, an organisation which has gone well beyond just medicine and looks at the role of expert witnesses from all walks of life, such as forensic accountants, engineers or any other discipline that requires an expertise, above and beyond lay knowledge, to ensure justice within the legal system.

The ACLM has not worked in a vacuum and an example of the wider acceptance of legal medicine, as a specific medical specialty, has been demonstrated by the partnership between the School of Medicine at Griffith University in Queensland, and the ACLM, in sponsoring the Master of Legal Medicine program at Griffith University. More recently there has also been an idea to offer post-graduate certificates and diplomas in legal medicine. The School of Medicine, at Griffith University, headed by Professor Judy Searle, has demonstrated an appreciation of the need to teach legal medicine to the medical profession around Australia. It has embraced the concept of teaching the discipline at a respected and academically acceptable level and the partnership between the ACLM and the University is further evidence of the need to recognise legal medicine as an important discipline within the wider delivery of health care.

As part of its recent review of services for sexual assault victims in New South Wales, KPMG, an internationally recognised, non-governmental company which may be contracted by other organisations, such as the government, to undertake a variety of projects (although it is best known for its accountancy practices), sought the input of the ACLM as a recognised peak body. Within the Australian context, a peak body is one that is accepted, on the basis of its standing within the community, to hold sufficient respect to be permitted to express a perspective which may be considered representative of opinion leaders in the field. Such a peak body is able to comment on behalf of those within a given field, which is under review, and for those opinions to be considered to be widely representative of the experts in that field.

This encouraged the ACLM to review its stand on the topic and assisted the review process to get input from people trained within legal medicine and the delivery of services in areas where both the practice of medicine and the practice of forensic science and medicine combine so easily. To practice one, without due consideration for the other, would destroy valuable evidence, fail to look after patients properly and has the potential to violate patient's rights. It is reassuring to see that not only does the ACLM see itself as a peak body, with the potential to provide critical input into the 
assessment of healthcare delivery, but government contractees, such as KPMG, have made unsolicited approaches to the College to seek its advice and consideration as a relevant peak body.

While the practice of legal medicine is determined by the jurisdiction in which it is applied, it is not an isolated parochial discipline but rather one that has international ramifications. The ACLM has developed close links with the American College of Legal Medicine, the FFLM and the World Association for Medical Law (WAML). So close are these ties that a significant number of ACLM Members and Fellows belong to these other organisations and have been acknowledged as world leaders in the field. The practice of legal medicine is coming of age when one realises that the ACLM and the FFLM, on other sides of the planet, are seeking the identical outcome to have legal medicine acknowledged as a demanding and recognised specialty in its own right.

\section{Patient Assessment}

Many doctors will recognise that legal medicine includes the assessment of disability and subsequent preparation of reports. This is clearly part of the commitment of legal medicine to the broader practice of public health. Legal medicine is indispensable when considering public health, recognising that the conflict between invasion of privacy and the need to report patients who have communicable diseases, psychiatric illnesses which may endanger themselves or others, conditions which restrict capacity for safe function (such as driving), are undeniably part of both legal medicine and public health.

Issues such as the alcohol level deemed relevant to activities such as driving, or how to deal with samples from patients in both everyday activities, such as patient assessments after accidents, as well as in sporting activities (with regards to performance-enhancing drugs and banned substances), must clearly be accepted as part of the overall practice of legal medicine with undeniable potential legal ramifications ensuing from what a doctor did, or did not, do.

The assessment of fitness to drive, fitness to fly, fitness to dive, fitness to undertake racing car driving and a host of other pursuits such as sporting activities, both nationally and internationally, all have legal medicine ramifications. Medical broadsheets, such as the Australian Doctor ${ }^{(3)}$, have recognised the legal medicine ramifications that can follow from such pursuits and the potential risk in classifying someone as fit to undertake such activities, should an unfortunate incident occur. It is now accepted that the doctor, who incorrectly assesses someone as fit to undertake such activities, may be the subject of litigation from an injured third party who suffered those injuries consequent to the activities which the doctor deemed to be safe. It is only with an appreciation that this risk occurs that doctors will change, or are changing, their behaviours and this is a direct consequence of the influence of legal medicine.

\section{Expert Witnesses}

It has already been stated that the ACLM was instrumental in the establishment of the EWIA but legal medicine encompasses all aspects of doctors being expert witnesses. It includes participation in court proceedings as well as expert report writing. It is relevant in patient assessments and interpretation of fitness to sign legal documents and evaluation of the capacity to decide for oneself or to require Guardianship supervision. The role of the doctor in legal proceedings has been the subject of wide commentary and the role that medicine plays in understanding what 
patients can, and cannot, do as responsible citizens, has reached an alarming level ${ }^{(4)}$.

In recognition of the fact that legal medicine is a discipline in its own right, the ACLM has gone on record to state that it is no longer acceptable to have legal medicine practised by doctors who no longer see themselves as being capable of delivering clinical services and thus choose to practice medicine as providers of expert witness reports in areas in which they previously practised as clinicians. The College has stated that it feels that legal medicine is sufficiently specialised to be a requisite adjunct to clinical understanding and delivery of health care and must be practiced in conjunction with patient contact and experience. As such, Fellows and Members of the College must have demonstrated sufficient post-graduation clinical experience to show that they have a good clinical basis upon which to make decisions, which respect the dictates of legal medicine. The College believes that the two are integral components of the same patient services. The ACLM believes that the clinician, practising in legal medicine, must have sufficient training to be able to provide the legal medicine component while still being current in their delivery of clinical management.

As part of its commitment to such recognition, the ACLM has established expert witness training programs which have been provided both within Australia and across the Tasman in New Zealand. These courses have not been restricted to constituents of the College but have been offered to those of other specialty bodies as a form of acknowledgement that the practice of legal medicine transcends the boundaries of other colleges.

In the same way as Fellows and Members of the College will access the specialties of other colleges, so other colleges have already started accessing the specialties provided by the ACLM.

\section{Sporting Activities}

It already has been stated that assessment for fitness to take part in a variety of activities is part of legal medicine but there are other ramifications within sporting activities which will take greater centre stage as legal medicine becomes more respected. The evaluation of sportsmen and women who are accused of assault, or even battery, because of on-field behaviour is worthy of consideration. It could be argued that to allow someone, subject to a head trauma, to continue to play a sport may be akin to medical negligence if that person has subsequent significant damage that was foreseeable and could have been avoided had the person been taken from the field.

A list of prohibited substances includes the obvious performance enhancement products, such as anabolic steroids, but it can also include routinely prescribed therapeutic agents. The doctor who innocently treats a medical condition with a medication, which subsequently is found to be on the prohibited list, may destroy an athlete's career, thereby creating the scenario of innocent negligence by the doctor and perceived wilful "doping" by the athlete by following good medical, but poor legal medical, practice. The emergence of sports medicine as a specialty area has parallelled the evolution of legal medicine but as sportsmen and women become one of the highest paid overall sectors of the community it will follow that the role of legal medicine, within the delivery of healthcare to athletes, will become of greater importance to ensure against oversights in prescribing habits which could destroy careers. 


\section{Ethics}

With a focus on medical research and the current criticism of the relationship between doctors and the pharmaceutical industry, the ethical practice of medicine is attracting far greater interest. Legal medicine is intimately involved with the consideration of ethical issues in health care. Those doctors who work in the field of ethics are usually dual qualified and hold legal training in addition to their medical qualifications. People within the ACLM have had major interest in questions dealing with ethical dilemmas and their interpretation. The Australian and New Zealand Institute of Health Law and Ethics (ANZIHLE) was founded through an understanding that all three disciplines interact and have interdisciplinary responsibilities. Fellows of the ACLM have served on the Board of ANZIHLE, and continue to do, thereby emphasising the intimate relationship that exists between ethical consideration and legal medicine.

It is unequivocal that one cannot practice one without the other, but just as one needs to have proper clinical exposure and experience to fully appreciate the interface between legal medicine and clinical practice, so should commentators be required to continue to have clinical exposure if they are to appropriately understand legal and ethical questions as they apply to health care and patient well-being. In the same way as expert witnesses must still remain clinically relevant and able to practice clinical medicine so it might be argued that within the legal medicine domain of ethical evaluation of patient management those same clinicians need to be clinically relevant and able to practice their discipline so that they have a clear understanding of how to judge from within, rather than criticise from without. The training that is provided in legal medicine, complementing clinical practice, provides a vehicle with which to offer relevant and pertinent ethical consideration within the context of the delivery of health care.

\section{The Wider Picture and International Considerations}

It is acknowledged that legal medicine does not work in a vacuum and should not be parochial, although it is determined by the jurisdiction in which it is delivered. International conventions, such as the Law of the Sea, the Geneva Convention regarding prisoners or The Declaration of Helsinki for Clinical Research have unequivocal legal medicine ramifications. One cannot undertake clinical research without respecting the Declaration of Helsinki ${ }^{(5)}$ which clearly outlines patient's rights and doctors' obligations with human subjects.

New South Wales is the first Australian state in which the courts have made it mandatory for a doctor to provide emergency service to a patient with whom he or she has never had a prior contractual or other relationship ${ }^{(6)}$. While this matter was heard in the Appellant Court it never reached the High Court of Australia but still offers a clear example of how legal medicine can impact significantly and change attitudes both for the doctors and the legal profession.

Questions of immigration and the monitoring of people coming into a country are further examples of how legal medicine impacts upon both international considerations and public health. The recent increases of syphilis and tuberculosis, particularly within the migrant population to Australia, are matters deserving of legal medicine consideration. The migration of patients with HIV Aids and the need for ongoing monitoring is especially relevant when one considers how often the psychological pressures of migration impact upon marriage and the subsequent dissolution of these marriages resulting in the potential for new relationships and the spreading of disease. 


\section{Forensic and Legal Medicine}

Many police surgeons and hence forensic physicians were part of the ANZFMS, which ultimately has become an integral component of the ACLM. It has already been stated ${ }^{(2)}$ that since its inception the ACLM has acknowledged two strands to legal medicine, that being the legal path or the forensic path and the marriage of the two within the ACLM, or the FFLM, clearly demonstrates the specialty status of this area of medical practice.

One cannot turn on the television, on any night of the week, without seeing unequivocal evidence which links forensic medicine, forensic pathology, policing and the underpinning of law and order. The fact that legal medicine has not yet been fully recognised as a subspecialty, particularly when one appreciates that legal medicine incorporates forensic medicine, is evidence of the administration of medicine not keeping pace with societal attitudes.

\section{Conclusions}

In conclusion, legal medicine is not a by-product of other disciplines but is a separate specialty in the area which deals with the growing interface between medicine and law. As such it must be recognised as a formal and demanding component of medicine and medical practice and requires sufficient training to demonstrate the necessary expertise needed to do it properly.

This overview has served to show that legal medicine requires purpose-driven instruction and evidence-based application to allow an optimal outcome. As has been the case with other medical specialties, it has evolved with time. The ACLM, over more than a decade, has played a critical role in refining the boundaries and delivery of legal medicine within the Australasian sphere of influence to assist the profession to understand that legal medicine is a fundamental and demanding specialty area. University academic recognition and provision of formally approved tertiary qualification have confirmed legal medicine to be a specialty area. This, coupled with the acknowledgement from other external organisations, such as other colleges and societies, which have actively sought the involvement of the ACLM, has underwritten both legal medicine in general, and the ACLM in particular, as a vital and necessary component of the profession and the delivery of health care.

\section{References:}

1. Rogers $v$ Whitaker (1992) 175 CLR 479; (1991) Aust Torts Reps 81-113 (NSW CA); (1991) 23 NSWLR 600

2. Beran R. G.

"The Teaching of Legal Medicine in Australasia"

J. Forensic \& Legal Med. (In Press)

3. McNamara S

"GPs warned over fitness to drive risk"

Australian Doctor, May 18, 2007 (p 6)

Babbington $\mathrm{G}$

"Lane change for drivers with epilepsy"

Australian Doctor May 18, 2007 (p 6) 
4. Samson C

"Brain scans gain momentum as forensic evidence, but jury is still out on its relevance"

Neurology Today 7 (7), April 3, 2007 (p 1, 12, 14)

(www.neurotodayonline.com)

5. World Medical Association Declaration of Health, Helsinki (1989) Recommendations Guiding Physicians in Biomedical Research Involving Human Subjects, Adopted by the 18th World Medical Assembly (WMA), Helsinki, Finland, June 1964 and amended by 29th WMA, Tokyo, Japan, Oct 1975; 35th WMA, Venice, Italy, Oct 1983; 41st WMA, Hong Kong, Sept 1989, 48th WMA General Assembly, Somerset West, Republic of South Africa, October 1996, and the 52nd WMA General Assembly, Edinburgh, Scotland, October 2000. Note of Clarification on Paragraph 29 added by the WMA General Assembly, Washington 2002 Note of Clarification on Paragraph 30 added by the WMA General Assembly, Tokyo 2004

6. Woods v Lowns \& Procopis, Court of Appeal, 5/2/96 ref: 40094/1995 